\title{
PHENINDIONE JAUNDICE
}

\author{
BY \\ T. HARGREAVES AND MARGARET HOWELL \\ From the Departments of Chemical Pathology and Hamatology, St. George's Hospital Medical School, London S.W.I
}

Received April 9, 1965

Twelve cases of jaundice due to phenindione have previously been reported. The jaundice has been described as hepatocellular (Makous and Vander Veer, 1954; East and Beamish, 1957), cholestatic (Burns and Desmond, 1958; Wallace, 1960), and combined hepatocellular damage with cholestasis (Portal and Emanuel, 1961; Perkins, 1962). Three further cases of phenindione jaundice are described here.

The site of action of phenindione in the liver causing jaundice has not been established with certainty. Sherlock et al. (1961) did not find any alteration in bilirubin, alkaline phosphatase, aspartate transaminase, and isocitrate dehydrogenase levels in 21 patients receiving long-term phenindione therapy. Fielder et al. (1961) administered 20-50 mg. $/ \mathrm{kg}$. phenindione to dogs daily for three months but did not find abnormal bromsulphthalein retention.

Using in vitro and in vivo systems we have examined the effect of phenindione on the conjugating mechanisms in the liver and on the excretion of pigments by the liver into the bile.

\section{CASE RePORTS}

Case 1. A 50-year-old woman known to have rheumatic heart disease was admitted with cerebral and coronary emboli. Serum aspartate transaminase was 114 units on admission. Eight days later it had fallen to 27 units and the serum alanine transaminase was 15 units. The patient recovered rapidly but because of the danger of further embolic crises she was started on phenindione therapy 20 days after admission and was then sent home. Twenty-six days after starting phenindione she began to feel ill with aching limbs and nausea and a generalized irritating rash appeared. She was seen as an out-patient five days later and phenindione was immediately discontinued, warfarin sodium being substituted. Quick single-stage prothrombin time was then 36.5 seconds (control 13.5 seconds). Five days after this she became jaundiced; there was generalized lymphadenopathy and she was readmitted. During the next ten days her symptoms improved and the rash and jaundice disappeared. The white cell count, which on admission had shown a neutropenia and eosinophilia, returned to normal and she was discharged. The results of liver function tests are summarized in Table I.

Case 2. A 42-year-old woman was admitted with a left hemiplegia. She was known to have valvular heart lesions and was fibrillating. Phenindione therapy was started immediately and intravenous heparin was given for $\mathbf{2 4}$ hours after admission. She made a rapid recovery from the nervous disorder and was sent home. Twenty-eight days after phenindione had been started the prothrombin time, previously well controlled, was 300 seconds and she gave a seven-day history of fever, nausea, malaise, and a generalized rash. She had also noticed that her urine was dark. Phenindione was immediately discontinued, and vitamin $\mathrm{K} 1$ (10 mg. konakion orally) was given. On admission to hospital the patient was pyrexial with an erythematous rash and generalized lymphadenopathy. The following day she was jaundiced. Liver function tests were abnormal (Table I) and there was a neutropenia. Her condition improved and, one week later, the jaundice was fading, but four days later her condition again deteriorated. She became oliguric, her blood urea rising to $240 \mathrm{mg}$. $/ 100 \mathrm{ml}$. After ten days there was a diuresis and she began to improve, her urea slowly 
TABLE I

Liver function Tests in Phenindione Jaundice

\begin{tabular}{|c|c|c|c|c|c|c|c|c|}
\hline $\begin{array}{l}\text { Case } \\
\text { No. }\end{array}$ & $\begin{array}{c}\text { Days after } \\
\text { beginning } \\
\text { phenindione }\end{array}$ & $\underset{(\mathrm{mg} . / 100 \mathrm{ml} .)}{\text { Bilirubin }}$ & $\begin{array}{c}\text { Alkaline } \\
\text { phosphatase } \\
\text { (K-A units } \\
/ 100 \text { ml.) }\end{array}$ & $\begin{array}{l}\text { Thymol } \\
\text { turbidity }\end{array}$ & $\begin{array}{l}\text { AST } \\
\text { units }\end{array}$ & $\begin{array}{l}\text { AIT } \\
\text { units }\end{array}$ & $\begin{array}{l}\text { Quick single- } \\
\text { stage prothrom- } \\
\text { bin time (sec.) }\end{array}$ & $\begin{array}{l}\text { White } \\
\text { blood cells/ } \\
\text { c.mm. }\end{array}$ \\
\hline \multirow[t]{2}{*}{1} & 39 & $1 \cdot 1$ & 21 & $1 \cdot 1$ & 83 & 54 & \multirow[t]{2}{*}{36.5} & \multirow{4}{*}{$\begin{array}{c}\text { Neutrophils } \\
900 \\
\text { Eosinophils } \\
1300 \\
\text { Neutrophils } \\
100\end{array}$} \\
\hline & 42 & 0.4 & 15 & $2 \cdot 7$ & 56 & 34 & & \\
\hline \multirow[t]{2}{*}{2} & 29 & 5.0 & 30 & $2 \cdot 2$ & 124 & 200 & \multirow[t]{2}{*}{300} & \\
\hline & 39 & 1.0 & 16 & $6 \cdot 6$ & & 98 & & \\
\hline \multirow[t]{3}{*}{3} & 35 & $2 \cdot 8$ & 37 & 1.2 & 115 & 252 & \multirow[t]{3}{*}{220} & \multirow{3}{*}{$\begin{array}{l}\text { Neutrophils } \\
\quad 300\end{array}$} \\
\hline & 41 & 1.4 & 22 & 1.0 & 17 & 30 & & \\
\hline & 44 & 0.8 & 25 & 2.0 & 13 & 16 & & \\
\hline
\end{tabular}

falling to normal levels, and she was eventually discharged. She has subsequently had a successful mitral valvotomy.

Case 3. A woman of 47 years with a popliteal vein thrombosis was placed on phenindione therapy. Twenty-eight days later she developed an erythematous rash together with anorexia, nausea, and vomiting. At examination six days later the prothrombin time was 220 seconds; the phenindione was immediately stopped and K1 given. She was admitted and found to be pyrexial and jaundiced. The results of liver function tests are shown in Table I. On admission the white cells were normal, but two days later there was a neutropenia together with many mononuclear cells. Her condition gradually improved and her liver function tests returned to normal. This patient has since had two further episodes of sensitivity reactions with a rash, the first of which was thought to be due to reaction to quinalbarbitone. The second episode for which no cause could be found was associated with an acute transitory psychosis. On neither occasion was the patient jaundiced.

\section{METHODS}

The rate of bilirubin glucuronide formation was estimated in rat liver slices and homogenates by the method of Lathe and Walker (1958). o-Aminophenol conjugation was measured in rat liver slices by the method of Levvy and Storey (1949), and in rabbit liver homogenates by the method of Stevenson and Dutton (1962). In the homogenate experiments uridine diphosphate glucuronic acid (Sigma Grade, Sigma Chemical Co.) was added in a final concentration of 0.3 millimol. The maximum hepatic clearance of bilirubin in Wistar rats was determined by the method of Weinbren and Billing (1956). The maximum hepatic clearance of conjugated bilirubin, bromsulphthalein, and indocyanine green was determined by infusing the substances into rats and determining their concentrations in the bile.

\section{RESULTS}

The addition of phenindione lowered the rates of conjugation of bilirubin and o-aminophenol by rat liver slices. The amount of conjugated bilirubin in rat liver slices conjugating bilirubin decreased with increasing concentrations of phenindione, but the unconjugated pigment was not reduced (Table II).

The transferase mechanism of conjugation was examined in rabbit liver homogenates incubated in a medium containing ample added uridine diphosphate glucuronic acid. Phenindione inhibited bilirubin and o-aminophenol conjugation in rabbit liver homogenates (Table III). Using rabbit liver microsomes at several substrate concentrations, without inhibitor and in the presence of 1 millimol. phenindione, a plot of $\frac{1}{\mathrm{v}}$ against $\frac{1}{\mathrm{~s}}$ (Lineweaver and Burk, 1934) showed a non-competitive type of inhibition of o-aminophenol conjugation by phenindione. 
TABLE II

Effect of Phenindione on Rate of Conjugation and Accumulation of Bilirubin IN RAT LIVER SLICES (Mean of 7 experiments)

\begin{tabular}{c|c|c|c}
\hline $\begin{array}{c}\text { Phenindione } \\
\text { concentration (mM) }\end{array}$ & $\begin{array}{c}\text { Rate of conjugation } \\
(\mu \mathrm{g} . / \mathrm{g} . / \mathrm{hr} .)\end{array}$ & \multicolumn{2}{|c}{ Bilirubin in slice } \\
\cline { 3 - 4 } & Total $(\mu \mathrm{g} . / \mathrm{g})$. & Conjugated (\%) \\
\hline 0 & 50 & 75 & 80 \\
0.01 & 27 & 73 & 60 \\
0.1 & 7 & 80 & 60 \\
10 & 3 & 68 & 35 \\
10 & & 34 \\
\hline
\end{tabular}

TABLE III

Phenindione and Conjugation (Mean of 4 experiments)

\begin{tabular}{c|c|c|c}
\hline & \multicolumn{3}{|c|}{ Rate of conjugation $(\mu \mathrm{g} . / \mathrm{g} . / \mathrm{hr})}$. \\
\cline { 2 - 4 } $\begin{array}{c}\text { Phenindione } \\
\text { concentration (mM) }\end{array}$ & $\begin{array}{c}\text { o-Aminophenol } \\
\text { Rat liver } \\
\text { slices }\end{array}$ & $\begin{array}{c}\text { Rabbit liver } \\
\text { homogenates }\end{array}$ & $\begin{array}{c}\text { Rabbitirubin liver } \\
\text { homogenates }\end{array}$ \\
\hline 0 & 95 & 523 & 210 \\
0.01 & 93 & 508 & 158 \\
0.1 & 82 & 369 & 140 \\
1.0 & 31 & 317 & 0 \\
10 & 9 & 123 & 0 \\
\hline
\end{tabular}

TABLE IV

Phenindione and Maximum Hepatic Clearance $(\mu \mathrm{g} . / 100 \mathrm{~g} . / \mathrm{min}$.

\begin{tabular}{l|c|c|c|c}
\hline & \multicolumn{2}{|c|}{ Control } & \multicolumn{2}{c}{ Phenindione (20 mg./100g.) } \\
\cline { 2 - 5 } & No. of experiments & Clearance & No. of experiments & Clearance \\
\hline Bilirubin & 14 & 75 & 4 & 55 \\
Conjugated & 6 & 43 & 4 & 57 \\
bilirubin & 7 & 73 & 4 & 63 \\
Bromsulphthalein & 12 & $4 \cdot 8$ & 4 & $5 \cdot 5$ \\
\hline
\end{tabular}

The effect of phenindione on the ability of the liver to excrete bilirubin, conjugated bilirubin, bromsulphthalein, and indocyanine green was determined on Wistar rats. Phenindione did not significantly decrease the biliary secretion of the pigments and dyes studied (Table IV).

\section{Discussion}

Phenindione jaundice usually appears during the fifth week of treatment, being preceded by a variable period of malaise, fever, and in some cases lymphadenopathy. The rash that normally accompanies these prodromal symptoms has in a few cases appeared with the jaundice or even a few days later (Perkins, 1962). Six patients with renal disease due to phenindione have now been recorded, of whom 4 died (Galea, Young, and Bell, 1963): in one the uræmia was associated with jaundice (Kirkeby, 1954). In the reported cases of phenindione jaundice, eosinophilia occurred in 7 , neutropenia in 3 , and atypical monocytes in 4 . Six patients developed exfoliative dermatitis. 
Abnormal results were obtained in all the usual tests of liver function except the thymol turbidity test. This does not preclude hepatocellular damage, as Hargreaves, Janota, and Smith (1961) found abnormal thymol turbidity readings in only 55 per cent of patients with viral hepatitis. The alkaline phosphatase was raised, being above $30 \mathrm{King}$-Armstrong units in 2 patients. In only 4 other patients have values above this level been recorded. In each patient reported here the serum transaminase levels were raised, indicating hepatocellular damage and confirming the observation of Perkins (1962) that serum transaminase estimation is the best biochemical indication of liver damage by phenindione, the serum alanine transaminase being the test of choice. The biochemical evidence presented here suggests that clinically the jaundice is of a combined cholestatic and hepatocellular type as suggested by Portal and Emanuel (1961) and Perkins (1962).

Phenindione illustrates some of the difficulties in testing for drug hepatotoxicity. Phenindione inhibits the in vitro formation of glucuronides, but it does not significantly depress the maximum hepatic clearance of bilirubin and other dyes.

The effect in vitro suggests that phenindione inhibits glucuronyl transferase. In the liver slice experiments phenindione reduces the conjugated pigment in the slice and in the medium, but it does not impair the entry of bilirubin into the slice. Phenindione reduces the rate of conjugation of o-aminophenol conjugation in both rat liver slices and rabbit liver homogenates; the drug inhibits the formation of ester and ether glucuronides. Schulert and Weiner (1954) reported levels of 16 $\mathrm{mg}$./1. (0.072mM) after therapeutic dosage. At this concentration phenindione inhibits glucuronyl transferase in vitro.

The effect of phenindione is greater in vitro than in vivo. It is unlikely that this is due to interference with the utilization of other factors in the in vitro estimation of glucuronyl transferase, for example, uridine diphosphate glucuronic acid, because added uridine diphosphate glucuronic acid does not overcome the inhibition. An alternative explanation is that the concentration of phenindione is insufficient to affect glucuronyl transferase in the intact animal. Experiments were performed to try and overcome this difficulty, but the lethal dose of phenindione is only slightly greater than the dose used in Table IV; the animal shows signs of central nervous system stimulation and muscle rigidity.

Phenindione jaundice is a mixed hepatocellular and cholestatic jaundice of relatively low incidence compared with other hepatotoxic drugs. It is possible that persons becoming jaundiced may be more susceptible in some way to phenindione than the general population. The drug depresses conjugation in in vitro preparations at therapeutic blood levels, but it does not reduce the biliary secretion of pigments and dyes, though it is secreted into the bile. This is similar to chlorpromazine (Hargreaves and Lathe, 1964). Some drugs, e.g. male fern extract, produce an unconjugated hyperbilirubinæmia in man (Nosslin, 1963) and inhibit glucuronyl transferase in vitro and in vivo in animals (Hargreaves, 1965). The animal experiments indicate that though conjugation is inhibited in vitro by each type of drug the response in the animal is variable. Male fern extract always produces some impairment of biliary excretion in man and animals, while phenindione occasionally produces liver dysfunction in man and does not impair biliary excretion in the rat. This possibly indicates that some other factor is involved in the intact animal and that further research will have to be directed to the patient who becomes jaundiced as a result of drug therapy.

\section{SUMMARY}

Three cases of phenindione jaundice are described. The patients recovered when the administration of phenindione was stopped. In animal preparations phenindione inhibits conjugation in in vitro preparations.

\footnotetext{
We should like to thank Dr. A. G. Leatham and Dr. J. F. Dow for permission to report these cases, Professor N. H. Martin for his advice and criticism, Evans Medical Limited for a generous gift of phenindione, and the British Empire Cancer Campaign and the Board of Governors, St. George's Hospital, for financial assistance. $3 N$
} 


\section{REFERENCES}

Burns, C., and Desmond, F. B. (1958). Sensitivity to Dindevan (phenylindanedione). Report of a case with review of the literature. N.Z. med.J., 57, 283.

East, E. N., and Beamish, R. E. (1957). Severe sensitivity reaction (hepatitis, dermatitis and pyrexia) attributable to phenylindanedione. Canad. med. Ass. J., 77, 1028.

Fielder, F. G., Hoff, E. J., Bolles, S., and Siegrist, J. C. (1961). A study of the chronic toxicity of anisindione and phenylindandedione in dogs. Toxicol. appl. Pharmacol., 3,122.

Galea, E. G., Young, L. N., and Bell, J. R. (1963). Fatal nephropathy due to phenindione sensitivity. Lancet, 1, 920.

Hargreaves, T. (1965). The effect of male fern extract on biliary secretion. To be published.

- Janota, I., and Smith, M. J. H. (1961). Multiple plasma enzyme activities in liver disease. J. clin. Path., 14, 283.

-, and Lathe, G. H. (1964). Drugs Affecting Biliary Secretion. Symposium on Therapeutic Agents and the Liver, London. Blackwell Scientific Publications, Oxford.

Kirkeby, K. (1954). Agranulocytosis following treatment with phenylindanedione. Lancet, 2, 580.

Lathe, G. H., and Walker, M. (1958). The synthesis of bilirubin glucuronide in animal and human liver. Biochem. J., 70, 705.

Levvy, G. A., and Storey, I. D. E. (1949). The measurement of glucuronide synthesis by tissue preparations. Biochem. $J ., 44,295$.

Lineweaver, H., and Burk, D. (1934). The determination of enzyme dissociation constants. J. Amer. chem. Soc., $56,658$.

Makous, N., and Vander Veer, J. B. (1954). Severe drug sensitivity reaction to phenindione (phenylindandione). J. Amer. med. Ass., 155, 739.

Nosslin, B. (1963). Bromsulphthalein retention and jaundice due to unconjugated bilirubin following treatment with male fern extract. Scand. J. clin. Lab. Invest., 15, Suppl. 69, p. 206.

Perkins, J. (1962). Phenindione jaundice. Lancet, 1, 125.

Portal, R. W., and Emanuel, R. W. (1961). Phenindione hepatitis complicating anticoagulant therapy. Brit.med.J., 2,1318 .

Schulert, A. R., and Weiner, M. (1954). The physiologic disposition of phenylindanedione in man. J.Pharm. exp. Ther., 110, 451.

Sherlock, S., Barber, K. M., Bell, J. L., and Watt, P. J. (1961). Anticoagulants and the liver. In Symposium on Anticoagulant Therapy, ed. Sir G. W. Pickering, p. 14. Harvey and Blythe, London.

Stevenson, I. H., and Dutton, G. J. (1962). Glucuronide synthesis in kidney and gastrointestinal tract. Biochem. J., $82,330$.

Wallace, D. C. (1960). Sensitivity to phenindione (“Dindevan"): report of two cases. Med. J. Aust., 1, 934.

Weinbren, K., and Billing, B. H. (1956). Hepatic clearance of bilirubin as an index of cellular function in the regenerating rat liver. Brit.J. exp. Path., 37, 199. 